"This document is the Accepted Manuscript version of a Published Work that appeared in final form in Catal.Sci.Technol. after peer review and technical editing by the publisher. To access the final edited and published work see:

http://dx.doi.org/10.1039/C7CY01136A"

\title{
Comparative Single Atom Heterogeneous Catalyst (SAHCs) on different platforms: A theoretical approach
}

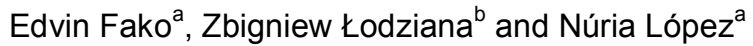 \\ ${ }^{a}$ Institute of Chemical Research of Catalonia, ICIQ, The Barcelona Institute of Science and Technology, Av. Països Catalans, 16, 43007 \\ Tarragona, Spain. E-mail: nlopez@iciq.es \\ ${ }^{b}$ The Henryk Niewodniczanski Institute of Nuclear Physics (IFJ-PAN), Radzikowskiego 152, 31-342 Krakow, Poland
}

Single atom heterogeneous catalysts, SAHC, have been considered as one of the holy grails in catalysis as they enable the best utilization of scarce and expensive catalytic noble metals. Obtaining atomic dispersion in a matrix is relatively easy but thermodynamics typically dictate the formation of nanoparticles, as roughly the cohesive energy per atom is gained by agglomeration. The nature of the SAHC interaction with the matrix is crucial as it controls the electronic structure of the atom, its charge, the coordination pattern (that might be different from a solid) and the overall catalytic ensemble. In order to avoid coalescence, SAHC interaction with the carrier can be strong enough that electron clouds of catalytically active atoms are compromised in bonds with the host lattice that they are made catalytically inert as no additional bonds can be formed. The dispersion of single catalytic atoms is controled by the relative bond strength between the metal and the matrix, the metals' own cohesive energy and the topology of active adsorption sites available in the matrix. As a consequence, a few classes of hosts including: metals, oxides, carbon nitrides, molecular crystals and Metal Organic Frameworks allow the efficient formation of SAHCs. So far, these matrixes have been examined independently and thus a common framework to study these SAHCs has not been proposed. Theoretical tools hold the key to investigate transversally the properties of the potentially catalytic metals in the different carriers and which is precisely the aim of the present work. We have checked all these aspects by studying the same single atom in oxides, metals and carbon nitride. Particularly we have found, that the nature of the different SAHCs is strongly dependent on the matrix as it affects the charge and position of the atomic levels. In addition, the matrix atoms can also participate in the reactions which has an impact in the overall SAHC reactivity illustrated by the interaction with hydrogen. With respect to SAHC stability, the major threat in these compounds, the most favourable case is found when cationic (still active) species are formed since coalescence is avoided by electrostatics.

\section{Introduction}

The catalytic activity, selectivity and stability of a heterogeneous catalyst are dictated by its physical structure and properties. Metals are among the best catalysts but many of them, the so-called noble metals, are scarce and thus expensive. The ultimate goal in hetereogeneous catalysis is the identification of the active sites ${ }^{1}$ from experiments, theory, or a combination of both, and their isolation that might help maintaining or even improving reactivity and selectivity of a catalyst whilst reducing the metal loading. This meliorates the efficiency of the catalyst per atom employed $^{2}$ which would have an undisputable economic impact. There have been indications that even single atoms can be important to a catalyst's performance just as much as nanoparticles. . $^{4}$

The implementation of the obtained rules brings us closer to the holy grail of heterogeneous catalysis, i.e. obtaining single-site heterogeneous catalysts (SSHC) that are identical in their atomic environment, spatially resolved and as dense as possible (or alternatively as accessible as possible in a porous matrix). ${ }^{5}$ The material needs to be simple enough to allow its production at the laboratory and its scalability for industry, ${ }^{6}$ with low proportions of expensive catalyst materials, and cheap materials as carriers. ${ }^{7}$ In order to achieve single atom dispersion the support matrix must provide surface geometry that anchors the metal atom into a favourable position overcoming the metals cohesive energy.

Although the idea of decreasing a metal's loading by increasing dispersion is logically sound, a question arises based on previous work as of which role single atoms play in heterogeneous catalysis. This question ${ }^{8}$ has been puzzling scientists since the methods for exploring it became available.

The reduction of particle size going from nanoparticles to the non-scalable regime, inevitably leads to lowercoordination number of metal centres, the modification of the metals electronic properties due to the confinement of the electrons, interactions with the support, and charge transfer. ${ }^{9}$ These effects can lead to improvements in a catalyst's properties. However, not all reactions can be catalysed with SAHCs, for instance when ensembles of atoms on the surface are needed. ${ }^{10}$ In addition, SAHCs can also improve selectivity provided that the desired path requires smaller ensembles than the alternative ones (i.e. hydrogenation of alkynes). Broad and comprehensive reviews of the 
numerous uses of SAHCs concern Brønsted's, and Lewis' acids, polymerization and photo-catalysts, ${ }^{11,}{ }^{12}$ or in renewable energy systems and materials, ${ }^{13}$ recently, even in micro-electronics. ${ }^{14}$

In this work, the state-of-the-art data on SAHC preparations and properties in different matrixes are summarized in Table 1 and serve as starting point for the discussion. Then, simulations based on Density Functional Theory ${ }^{15}$ are introduced for the study of these SAHCs as they hold the key to unravel the best stoichiometry and geometry for a relevant chemical transformation. Therefore, the same theoretical framework can be employed to study a noble metal, $\mathrm{Pt}$, when introduced as a SAHC on different carriers (supports) including a metal: $\mathrm{Cu}$; an iron oxide; and a carbon nitride. The properties of these SAHC are then evaluated by the electronic structure, stability and activity towards $\mathrm{H}_{2}$. This procedure allows identification of the differences between carriers and sets a common platform for the study.

SAHCs can be produced by the intrinsic properties of an alloy segregating the single atom to the surface; or by defects; or by atom substitution in oxides or on coordination sites inherently present in the material. Classified by different matrixes the state-of-the-art SAHC can be summarized as follows:

\section{Metals}

Near surface diluted alloys and diluted surface alloys are sometimes referred to in literature as single-atom alloys (SAA). Some SAAs have been subject to theoretical and experimental investigation with promising results. Cu has been shown to be a suitable inert matrix weakly interacting with $\mathrm{H}_{2}$. However, when low amounts of $\mathrm{Pd}$ are added, $\mathrm{Cu}$ can activate hydrogen. ${ }^{16,17}$ Due to the isolation of active sites one can expect to have much more control over the reaction selectivity on such a catalyst. Selectivity is most often achieved by eliminating competitive processes which require the existence of two or more neighbouring sites. This improves the yield and/or turnover rate of the favoured reaction. Such effect is precisely the case in the hydrogenation of styrene and acetylene on a Pd/Cu SAA. In short, the conversion of acetylene to ethylene, appears because of the $\mathrm{H}$ spillover towards $\mathrm{Cu}$, where acetylene is adsorbed, and due to the fact that the product, $\mathrm{C}_{2} \mathrm{H}_{4}$, is weakly adsorbed in the $\mathrm{Cu}$ areas. ${ }^{16,17}$ The resistance towards poisoning by small molecules that adsorb strongly on two- and three-fold sites of the active $(\mathrm{Pd})$ metal is improved by eliminating those ensembles. ${ }^{18}$ Hydrogen spillover has also been experimentally observed on a Pt/Cu SAA, ${ }^{19}$ indicating that other metals can be suitable SAHCs in $\mathrm{Cu}$ and actually tested the hydrogenation of butadiene to butane.$^{20}$ In addition, $\mathrm{Pt} / \mathrm{Cu}$ SAAs dehydrogenates formic acid with better selectivity but it shows worse activity than $\mathrm{Pt}$ nanoparticles on $\mathrm{Cu}{ }^{21}$ Finally, a theoretical screening of SAA bimetal systems has indicated that Rh alloyed with Au could have favourable properties for $\mathrm{CO}$ reduction. ${ }^{22}$

\section{Oxides}

The crystal structure of metal oxides presents wider structural diversity than that of metals. In principle, the embedded single atoms can occupy both anionic and cationic positions; cations are most likely to be replaced. The aliovalent metal substitution can generates unusuall coordination spheres, not present in their stable oxides. As a result, the static, dynamic, and reactivity properties are affected. A wide range of oxides have been used as SAHC carriers, most of them are characterized by showing a large reducibility and several redox states.

Two of the first oxide-supported SAHCs were Pt and $\mathrm{Au}$ on $\mathrm{CeO}_{2}$. These SAHCs were tested for the water-gas-shift reaction (WGS), and their activity was attributed to the existence of non-metalic $\mathrm{Pt}$ and Au species. ${ }^{3}$ Another classical example is $\mathrm{Au}$ on $\mathrm{TiO}_{2}$. For these materials $\mathrm{Au}$ atoms reduce the vacancy formation energy. ${ }^{23}$ This easing of vacancy formation can be observed also for the Fe-doped $\mathrm{MoO}_{3}$ employed in the selective production of formaldehyde from methanol, although this catalyst was never described as a SAHC. ${ }^{24}$ More complex architectures have been developed. An alternative way to link atoms to oxides surface is the use of ligands, binding with both the surface of the oxide and metal atoms. ${ }^{25}$ The surface of $\mathrm{TiO}_{2}$, in the form of nanosheets decorated with ethylene glycolate as anchors for Pd atoms, has shown an order of magnitude greater performance compared to commercial catalyst in the hydrogenation of $\mathrm{C}=\mathrm{C}$ bonds. The same catalyst hydrogenates aldehydes illustrated 55 times faster than the commercial counterpart whilst maintaining stability. ${ }^{25}$

Iron oxides have been the most recurrent platforms for SAHC formation, and they were actually responsible for the reinvention of the field in $2011 .{ }^{26}$ Magnetite $\left(\mathrm{Fe}_{3} \mathrm{O}_{4}\right)$ surfaces decorated with $\mathrm{Au}$ atoms have shown great stability at increased temperatures. This indicates strong single atom-matrix interactions, where adsorbed Au atoms favour only one type of sites formed by surface relaxation. ${ }^{27}$ The strength of the bond between $\mathrm{Pd}$ single atoms and the support can explain the lack of activity in alkene hydrogenations reactions when compared to small $\mathrm{Pd}$ clusters. ${ }^{10} \mathrm{Pt}$ atoms on a $\mathrm{FeO}_{x}$ carrier have been shown to be strongly bound and were assigned a positive charge. ${ }^{26} \mathrm{Ir}_{\mathrm{r}} \mathrm{FeO}_{\mathrm{x}} \mathrm{SAHC}_{\mathrm{present}} \mathrm{a}$ higher activity in the water gas-shift reaction (WGSR) over Pt and Au catalysts. ${ }^{28}$

$\mathrm{CoO}$ considered as a single Rh atom support has shown nearly full selectivity in addition to high turnover rates for the hydroformylation of propene. ${ }^{29}$ Singly dispersed bimetallic sites (SBMS) of $\mathrm{Rh}_{1} \mathrm{Co}_{3}$ composition were synthetized by oxidation and reduction processes on $\mathrm{CO}_{3} \mathrm{O}_{4}$ and exhibit exceptional performance and selectivity for the reduction of $\mathrm{NO}$ to $\mathrm{N}_{2}{ }^{30}$ Other early transition state metal oxides, like manganese oxide rods, have been shown to produce Ag SAHCs. ${ }^{31}$ Finally, a non-reducible oxide, alumina was tested as a support for $\mathrm{CO}$ oxidation catalysts that stabilises both $\mathrm{Pt}^{32}$ and $\mathrm{Pd}^{33}$ atoms. 


\section{Modified carbons}

Carbons have emerged as one of the most powerful supports for SAHC as they can be fine-tuned by doping. Metal atoms are in general prone to surface diffusion on the graphene basal plane, hence it is necessary to provide anchor points for those atoms in order to prevent dimer formation and atom agglomeration. These anchor points can be introduced to the carbon support trough doping. N, P, S, O (and other) doped graphites, graphenes, carbon nanotubes (CNT), as well as carbon nitride materials have shown promise as SAHC supports. For nitride and carbide materials as SAHC supports a new insight for the interplay between effects related to strongly hybridized support and properties of a single atom catalyst were provided recently. ${ }^{52}$

Metal diffusion and agglomeration was observed on graphene based materials, although spillover was achieved through Pt nano-particles (NP). ${ }^{53}$ Graphyne monolayers were modelled to show that there is a possibility of creating an atomic dispersion of $\mathrm{Rh}$ ( $\mathrm{Au}, \mathrm{Pt}$, Ir and $\mathrm{Pd}$ ) capable of oxidizing $\mathrm{CO}$ at low temperatures. ${ }^{34}$ In addition, surface curvature might have role and some results suggest that Au single atoms on multi-walled carbon nanotubes (MWCNT) could be more reactive than nanoparticles. ${ }^{35}$ Zhang and co-workers proved the existence of $\mathrm{Nb}$ atoms and ultrafine clusters in onion like graphitic shells and showed their activity. $\mathrm{O}_{2}$ molecules can penetrate to the core of these structures. ${ }^{50}$

$\mathrm{N}$-doped graphene has shown potential for stabilising several atomic species. It has been tested in combination with $\mathrm{Pt}$ atoms for $\mathrm{CO}$ oxidation, ${ }^{37}$ while a correlation between the formal charge assigned to $\mathrm{Pt}$ atoms and the affinity towards $\mathrm{O}_{2}$ has been established. ${ }^{36} \mathrm{Co} / \mathrm{N}$-doped graphene SAHC has shown to be highly active regardless of the $\mathrm{pH}$ of the medium for the hydrogen evolution reaction (HER). ${ }^{39}$ It has been shown that in-plane $\mathrm{N}$ defects on graphene can stabilise $\mathrm{Fe}$ atoms. It is also suggested that the oxygen reduction reaction activity of these materials originates from inplane sites, rather than edge defects. ${ }^{40}$ Co-doping is also possible, Fe adsorbed N-S co-decorated showed bifunctional behaviour, and hold promise for both the oxygen reduction reaction (ORR) and oxygen evolution reaction (OER) showing great stability in metal-air batteries. ${ }^{41}$

Increasing the dopant amount can be done only up to a certain extent before the obtained material cannot be considered a "modified support" and becomes a material on its own; like in the case of N doped graphite. Graphitic carbon nitride $\mathrm{g}-\mathrm{C}_{3} \mathrm{~N}_{4}$ has higher content of nitrogen than carbon. Although it is similar in structure to graphite, in the sense that both have crystal phases consisting of stacked layers of hexagonal building blocks. The main difference is that $\mathrm{g}-\mathrm{CN}$ has periodically separated metal coordination sites. The larger unit cell is represented at the bottom of Figure 1. Then, the $\mathrm{Pd}$ atoms occupy the pockets and are isolated. This material is active in the hydrogenation of alkynes and nitroarenes. ${ }^{38}$ The stability and aggregation patterns of $\mathrm{Pd}$ or $\mathrm{Pt}$ in $\mathrm{g}-\mathrm{C}_{3} \mathrm{~N}_{4}$ were investigated by DFT and kinetic Monte Carlo. It is the high intrinsic presence of coordination pockets (generated by the removal of some $\mathrm{C}$ from the ideal graphyne layer) that allows high dispersion of single atoms at low metal concentrations making them dynamically stable. ${ }^{46}$ When less precious metals such as Co are nested at the coordination sites of the carrier, they become active in oxygen electrode reactions. ${ }^{44}$ Several metal-containing graphitic $\mathrm{C}_{2} \mathrm{~N}$ materials were computationally tested for the oxygen reduction reaction (ORR) under electrochemical conditions. ${ }^{45}$ Moreover, carbon nitride materials also show promise as photochemical catalysts and their behaviour has been investigated both experimentally ${ }^{54,55}$ and, when combined with transition metal atoms, theoretically. ${ }^{42,43}$ The electronic attributes vital for their photocatalytic activity are connected to their layered structure, as 2D materials are known to have unique electronic properties. ${ }^{56}$

Oxygen-doped graphitic materials are also popular because of the relative ease of introducing $O$ defects to graphene slabs. When an $\mathrm{O}$ atom is introduced (in the form of hydroxyl, carboxyl, peroxide, epoxide... ${ }^{57}$ ) changes are induced to the electronic structure surrounding atoms. For instance, the activity of gold atoms dispersed on hydroxylated graphite have been correlated to the Hirshfeld charges and formal oxidation states suggesting the crucial role of charge transfer ${ }^{48}$ towards the acetylene hydrochlorination. In hydrogenation reactions, these types of materials preserve their high selectivity and good performance attributes. In fact, O-doped graphitic materials have been shown to be exceptional supports for highly dispersed Pd particles and atoms in the hydrogenation of butadiene to butane, exhibiting favourable selectivity, durability and low coking ${ }^{49}$.

The doping of graphitic materials with sulphur can result in peculiar structural changes. Sulphur-doped graphene nanoribbons doped with a high amount of $S$ have been shown to be very successful stabilising on high amounts of atomically dispersed $\mathrm{Pt}^{51}$

\section{Other Compounds}

Traditionally, zeolites were taken as examples of single atom catalysts, typically cations obtained by ion exchange. ${ }^{5}$ Also grafting of organometallic complexes on silica-type compounds ${ }^{58}$ have been proposed as active sites in polymerizations ${ }^{5}$ and other reactions. ${ }^{59}$ However, in both cases the systems offer an extra-framework as the atoms are not incorporated in the lattice. Moreover some zeolites have shown an interesting behaviour when interacting with $\mathrm{Pt}$ atoms and nanoparticles, showing reversible transformation from nano- to single atom dispersion. ${ }^{60}$ As the studies on exchanged zeolites and anchored organometallic systems have been subject to other revisions they are not discussed in the present work. ${ }^{9,61,62}$ Other matrixes 
like Double metal cyanides $(\mathrm{DMC})^{63,64}$, and more recently Metal Organic Frameworks (MOF) ${ }^{65-67}$ have been introduced for single site isolation. For DMCs and MOFs there are no reports on Pt substitution in the literature and thus, although they have potential as matrixes they have not been included in the pool of prospective platforms for the calculations that we present here.

\section{Computational Details}

Density functional theory (DFT) simulations were performed using the VASP code. ${ }^{68,69}$ All model systems are presented in Figure 1. The functional used was PBE. ${ }^{70}$ Inner electrons were replaced by PAW. ${ }^{71}$ while 16 valence electrons were included for $\mathrm{Pt}, 5$ for $\mathrm{N}$ and 4 for $\mathrm{C}$ for the carbon nitride systems. For other systems 10 valence electrons were considered for $\mathrm{Pt}, 8$ for $\mathrm{Fe}, 6$ for $\mathrm{O}$ and 11 for $\mathrm{Cu}$. The kinetic energy cutoff of the plane wave basis set was set to $450 \mathrm{eV}$ for the carbon nitride systems, and $500 \mathrm{eV}$ in all other cases. The $\mathrm{U}$ parameter was added in the description of the oxide although for the $\mathrm{Fe}$ cation $\mathrm{U}_{\mathrm{eff}}=4.5 \mathrm{eV} .^{72}$

The Cu slab contained eight layers in a $\mathrm{p}(4 \times 4)$ reconstruction where only one of the surface (subsurface or bulk) atoms was replaced by $\mathrm{Pt}$. The topmost 4 layers were allowed to relax. The k-point sampling was $3 \times 3 \times 1$. The oxide, $\square-\mathrm{Fe}_{2} \mathrm{O}_{3}$ system, was represented by a 6-layer slab. The stoichiometric (0001) surface is known to be polar thus it was terminated by halve monolayer of Fe. The magnetization of the system was taken into account and the proper solution was chosen in each case following the procedure in ref. [72]. Half of the slab was allowed to relax, only one Fe cation was replaced by $\mathrm{Pt}$ either in the bulk or in different surface positions. For $\mathrm{g}-\mathrm{C}_{3} \mathrm{~N}_{4}$ dispersion van der Waals-like contributions are important to explain the stacking of the graphene layers and it was introduced through the D3 approach. ${ }^{73}$ The k-point sampling was $5 \times 5 \times 5$ and $3 \times 3 \times 1$ for the bulk and modelled surfaces respectively. The bulk relaxations were performed on two layer cells, one with the layers translated in reference to each other by a/3 along (0010) direction ( $\mathrm{g}-\mathrm{CN}-\mathrm{n}$ ) and the other with the layers rotated by $180^{\circ}$ around the $(0001)$ direction as shown in Figure 1. The surfaces were modelled with 4 layers separated by $12 \AA$ of vacuum employing a dipole correction along the $z$ axis.

The formation energies of dimers with respect to those of two isolated surface atoms need to be taken with care as the entropy factor could provide additional stability to the single atom dispersed configuration. These entropic contributions can be calculated as $S=-x R \ln x$, where $x$ is the concentration. The stability concerns when employing Pd as metal platform are previously addressed by theoretical investigation and the same methodology shall be applied here. ${ }^{74}$

\section{Results}

The comparative analysis of the different SAHC systems has been performed at different levels, see Figure 2 . For instance, the facility to form the SAHC can be represented by the solubility, i.e. the propensity to incorporate the SAHC atom to the matrix. Solubility is the propensity to replace or incorporate the SA in the material and can be written as: $E_{s o l}=E_{w}+E_{M}-E_{P t, b}-E_{c l}$, where $E_{w}$ is energy of the support with the metal in the $w$ position; $E_{M}$ the energy of the replaced host atom in its bulk; $E_{P t, b}$ is the energy of bulk $\mathrm{Pt}$, and $E_{c l}$ the energy of the host clean surface. For the oxide case, the equation is modified as the $E_{M}$ corresponds to the bulk $\mathrm{Fe}_{2} \mathrm{O}_{3}$ energy and the equation is balanced with $\mathrm{O}_{2}$ to account for stoichiometric changes.

The values show that while forming a dispersion of $\mathrm{Pt}$ in another metal like $\mathrm{Cu}$ is relatively easy, only moderately endothermic with respect to the bulk metal, the situation is worse for the CN matrix or when embedded as cations. Therefore, SAHCs are thermodynamically metastable configurations. The second stability-related terms are the surface and subsurface configurations that are measured through the segregation energy $E_{\text {seg }}$ and near surface alloy formation energy $E_{N S A}$ as the difference between the energy of the system with the atom in the $w$ position versus the energy of the system with atom in the surface and subsurface positions $s$ and $v$ position, $E_{s e g}=E_{s}-E_{W}, E_{N S A}=E_{v}-$ $E_{w}$, respectively. Segregation towards the surface is favoured for $\mathrm{Cu}$ and some $\mathrm{CN}$ but not favourable for the oxide. Actually, near surface positions are the most energy favoured for iron oxide matrix. The difference in the surface and subsurface positions for the oxide are remarkable, almost $1 \mathrm{eV}$, and indicate that the models employed for SAHCs in oxides might be too simple.

The propensity to form dimers is also a severe concern when preparing SAHCs and can be taken as first descriptor to analyse agglomeration. In the case of Pt the gas-phase dimer formation energy is exothermic by $3.25 \mathrm{eV}$. In Figure 2 islanding is represented by $E_{i s l}=E_{d}+E_{c l}-2 E_{s}$ where $E_{d}$ are the energies of a dimer on the surface. For Pt, islanding might occur on $\mathrm{Cu}$, therefore the concentration on the surface needs to be accurately controlled in order to get SAHCs. On the $\mathrm{CN}$ platforms the polarization of the bond diminishes islanding and the most likely isolated atoms can be obtained for the iron oxide matrix.

The state of the atoms in the platforms can then be analysed by computing the $d$-band centre of Pt, and by studying the Density of States, see Figure 3. The degree of metal-support overlap and electron sharing depends strongly on the platform where the SAHC is generated. When forming the alloy the Pt $d$ and $s$ states are completely mixed with $\mathrm{Cu}$ 
over a broad range of energies. The final effect is that the charge of Pt (Bader charge: $-0.68\left|\mathrm{e}^{-}\right|$) is close to the nominal value and only the $d$-states are shifted $0.47 \mathrm{eV}$ towards negative values with respect to Pt bulk (see Figure 2). The situation for $\mathrm{Pt}$ in the oxide (Bader charge: $1.17\left|\mathrm{e}^{-}\right|$) is similar in the sense that the $d$-band is stabilized but now the $\mathrm{Pt}$ states are depleted in the top of the valence-band of the oxide. This means that the $d$-states are less available for bonding. Finally, the situation for the $\mathrm{CN}$ materials is the most striking (Bader charges: g- $\mathrm{CN}-\mathrm{n} 0.45\left|\mathrm{e}^{-}\right|$; g- $\mathrm{CN}-\mathrm{r} 0.55 \mid \mathrm{e}^{-}$ |), the $\mathrm{CN}$ has localised bonds which are quite narrow and thus the interaction with the metal is only produced with some of these states. From the point of view of level separation, $\mathrm{CN}$ seems the best platform to keep the isolated nature of the SAHC in the form of almost separated energy levels. The particular position of the aromatic rings in the $\mathrm{g}-\mathrm{CN}$ seems to have a large effect in the particular properties of the Pt centers.

The so-prepared systems were then tested for their ability to activate $\mathrm{H}_{2}$, see Figure 4 . As the platforms are different, homolytic activation is found to be preferred for the metal matrix while heterolytic bond breaking ${ }^{75}$ occurs both for the oxides and the $\mathrm{CN}$ platform. The reaction is exothermic in all cases and the stabilization depends on the nature of the system with the g-CN-r representing the most exothermic reaction. This energy difference between the $\mathrm{CN}$ systems can be qualitatively described by two descriptors, matrix deformation energy, and the geometric aromaticity parameter HOMA. $^{76}$ Matrix deformation energies account for most of the difference (about $1 \mathrm{eV}$ ), with the aromaticity lessening the total discrepancy. On the metal system, $\mathrm{H}_{2}$ activation takes place with no noticeable barrier, thus is similar to the $\mathrm{Pt}$ metal alone and contrarily to $\mathrm{Cu}$ alone, for which a barrier of about $0.6 \mathrm{eV}$ exists. Therefore, the neighbouring $\mathrm{Cu}$ metal provides a very similar environment to the one in pure $\mathrm{Pt}$ that does not affect activation. This explains the activation observed in the experiments and the fact that spillover occurs. ${ }^{19}$ For the oxide, Pt reduces the barrier from 0.49 for $\mathrm{Fe}_{2} \mathrm{O}_{3}$ to $0.31 \mathrm{eV}$ when located on the surface. Even when the atom is sitting in the near-surface (the most stable configuration as shown in Figure 2) some promotion exists and the barrier is $0.47 \mathrm{eV}$. The barrier for the $\mathrm{g}-\mathrm{CN}-\mathrm{n}$ is the largest (about $0.66 \mathrm{eV}$ ). The reason for that can be traced back to the lowest charge separation when compared to the oxide and implies that $\mathrm{CN}$ platforms active metals are needed for SAHC as the perturbation with the scaffold is small, Figure 3. The transition state geometries for the heterolytic activations show the role of the neighbouring atoms to the $\mathrm{SAHC}$ in the hydrogen activation process.

Finally, long terms dynamics in the presence of hydrogen might affect the performance as the stable phases might vary in high hydrogen pressures. This has been evaluated at the hydrogen induced segregation energy, $E_{H s e g}=E_{S H}-$ $E_{w}-E_{H m}$, where $E_{S H}$ is the SAHC with adsorbed hydrogen and $E_{c l H}$ is the energy for the clean surface with hydrogen, see Figure 2. Induced segregation favours the metal in metal configuration and some of the $\mathrm{CN}$ ones but it is strongly disfavoured for $\mathrm{Fe}_{2} \mathrm{O}_{3}$ which indicates that the metal-on-metal segregation is the easiest to control. Therefore, significant effects are envisaged when working at high pressures for the isolated atoms in metals.

\section{Conclusions}

Single Atom Heterogeneous Catalyst might be synthetised in a number of scaffolds and their particular properties in terms of stability and activity depend strongly on the matrix chosen. We have revised the literature to assess the fastest growing areas in the formation of SAHC and then performed a detailed characterisation of stability parameters, electronic structure and activity towards $\mathrm{H}_{2}$ activation. We have found that the impact of the scaffold is very large and explains the wide variety in the behaviours observed. From the single atom perspective, i.e. isolation terms, oxides seem to be a nice environment as the charges carried out by the SAHC as a cation prevent agglomeration, however, the reactivity on the material might completely rely on the native platform and the metal is only modifying the redox properties of the oxide. In addition, most commonly investigated surface locations for the SAHC might not be the thermodynamic sinks thus compromising long-term activity. Alternatively, more traditional metal-on-metal systems suffer from segregation and induced segregation effects should a reactive environment be present. The new class of scaffolds based on $\mathrm{CN}$ seems to balance the two aspects whilst keeping activity at the SAHC a nice control of the number of nesting positions gives a larger control on the long term properties of these materials.

\section{Acknowledgements}

We thank MINECO (CTQ2015-68770-R) for financial support. E.F. thanks La Caixa-Severo Ochoa for a predoctoral grant. CPU allocation at PL-Grid infrastructure is kindly acknowledged. The authors gratefully acknowledge the help of Prof. M. Swart on the description of aromaticity. 


\section{Figures and tables}
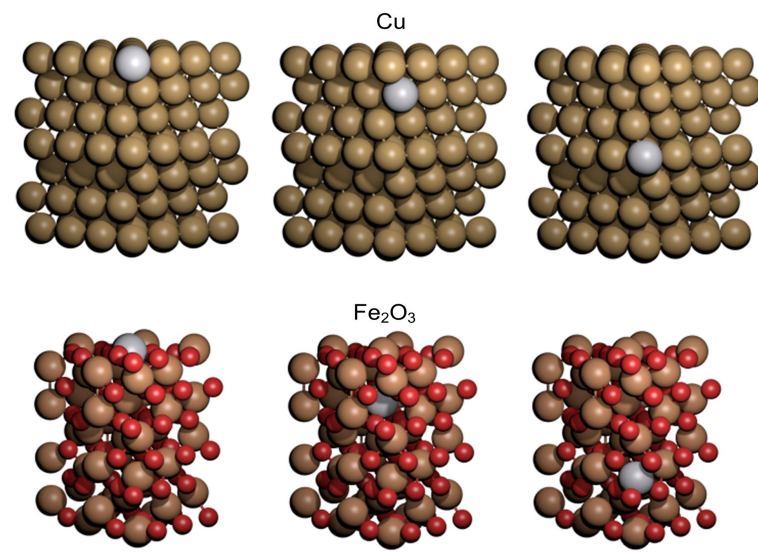

g-CN-n

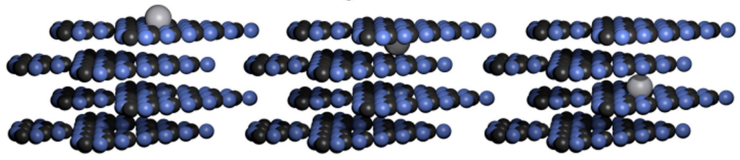

g-CN-r

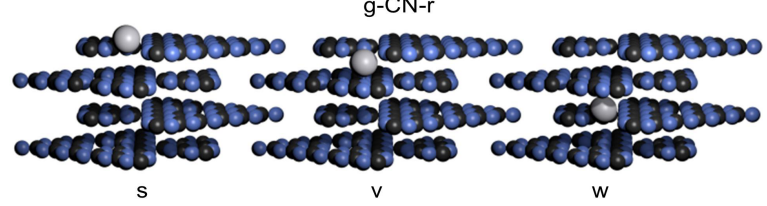

$\odot \bullet \bigcirc \bullet \bullet \bigcirc$

Figure 1. Model systems employed in the theoretical simulations. Top, Cu matrix, centre $\mathrm{Fe}_{2} \mathrm{O}_{3}$ one and bottom two different configurations for $\mathrm{C}_{3} \mathrm{~N}_{4}$ materials we have investigated a collection of parameters for a SAHC formed by a Pt atom in different matrix.

\begin{tabular}{|c|c|c|c|c|}
\hline & $\mathrm{Cu}$ & $\mathrm{Fe}_{2} \mathrm{O}_{3}$ & $g-C N-r$ & g-CN-n \\
\hline $\mathrm{E}_{\mathrm{sol}}$ & 0.29 & 3.38 & 0.62 & 0.95 \\
\hline$E_{\text {seg }}$ & -0.18 & 0.77 & 0.07 & -0.27 \\
\hline $\mathrm{E}_{\mathrm{NSA}}$ & 0.01 & -0.24 & -0.52 & -0.22 \\
\hline $\mathrm{E}_{\mathrm{isl}}$ & 0.18 & 3.22 & 1.68 & 2.26 \\
\hline$\varepsilon_{\text {d-cen }}$ & -2.58 & -3.10 & -2.83 & -1.95 \\
\hline $\mathrm{E}_{\mathrm{Hseg}}$ & -0.77 & 0.74 & -1.40 & -0.89 \\
\hline
\end{tabular}

Figure 2. Heat map of the calculated stability properties of the modelled single atom catalysts. The definitions Esol solubility energy, Eseg segregation energy, ENSA near surface alloy formation energy, Eisl islanding energy, EHseg hydrogen stimulated segregation energy, $\varepsilon d$-cen $d$ band centre energy. All energies in eV. 


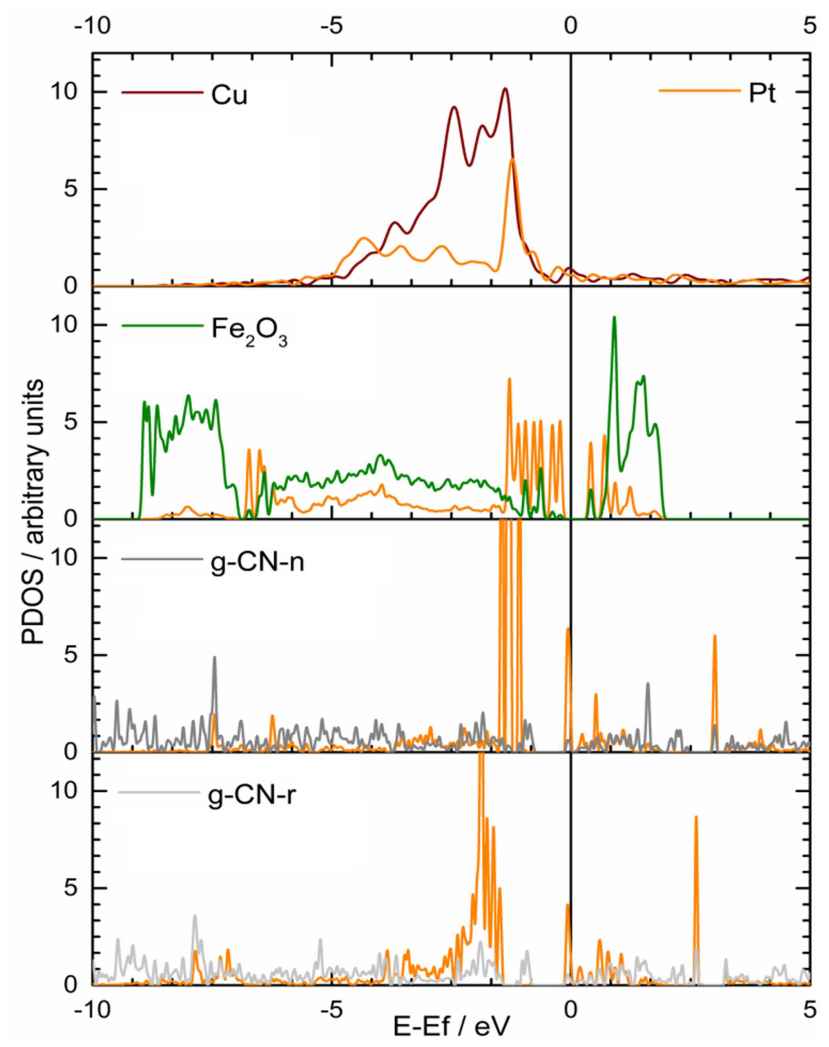

Figure 3. Projected density of states for all calculated systems, shown in red, green, and gray is the total (up+down spins) density of states projected on the atoms of the support, Pt is represented in orange.

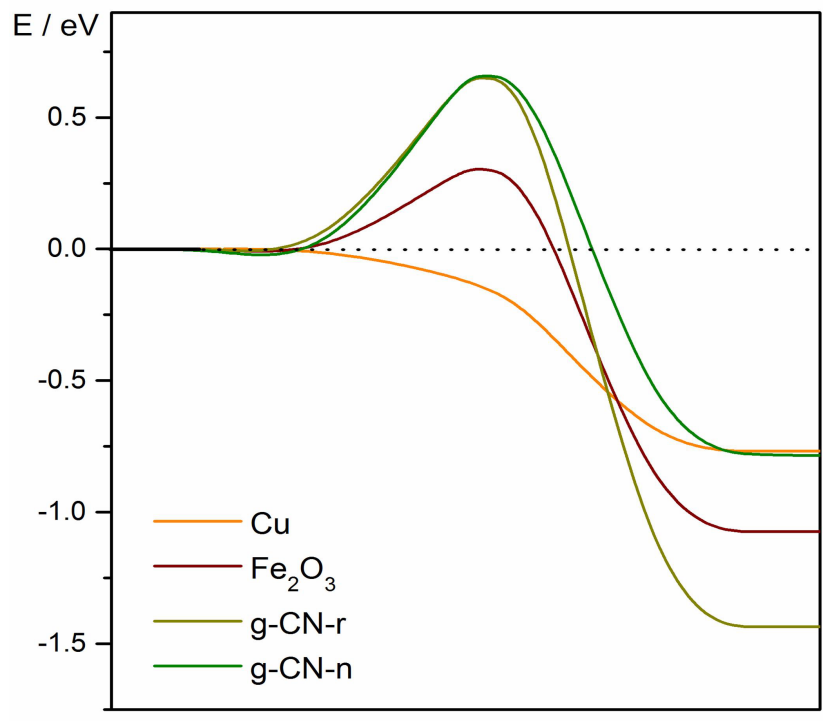

Reaction Coordinate

Figure 4. Reaction profile of the hydrogen dissociation on the investigated single atom catalysts. The energies are calculated with regard to reactants, (i.e. the isolated hydrogen molecule, and the surface). The products represent systems with the $\mathrm{H}-\mathrm{H}$ bond broken 


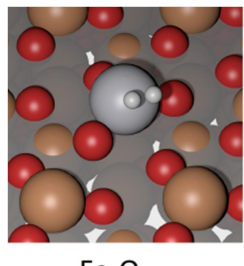

$\mathrm{Fe}_{2} \mathrm{O}_{3}$
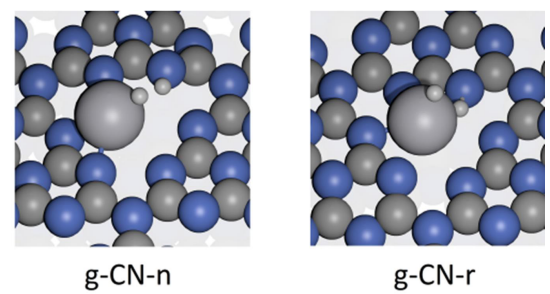

Figure 5. Transition state geometries for the iron oxide, and carbon nitride systems. The Cu system is not shown since the dissociation is a barrierles process on that surface. 
Table 1. Some of the most studied cases of Single Atom Heterogeneous Catalyst proposed in the literature.

\begin{tabular}{|c|c|c|c|c|c|}
\hline \multicolumn{2}{|l|}{ Support } & \multirow{2}{*}{$\begin{array}{l}\text { Metal } \\
\text { Pd }\end{array}$} & \multirow{2}{*}{$\begin{array}{l}\text { Use } \\
\text { Hydrogenation of styrene and } \\
\text { acetylene }\end{array}$} & \multirow{2}{*}{$\begin{array}{l}\text { Highlights } \\
\text { UHV study, 95\% selectivity }\end{array}$} & \multirow{2}{*}{$\frac{\text { Ref. }}{16}$} \\
\hline Metals & $\mathrm{Cu}$ & & & & \\
\hline & $\mathrm{Cu}$ & $\mathrm{Pd}$ & Semihydrogenation of acetylene & $\begin{array}{l}\text { Simulated Front-End Conditions, } 85 \% \text { selectivity, high } \\
\text { conversion }\end{array}$ & 17 \\
\hline & $\mathrm{Cu}$ & $\mathrm{Pt}$ & $\begin{array}{l}\text { Hydrogenation of } \\
\text { 1,3-butadiene }\end{array}$ & Stable activity at $100 \%$ selectivity & 20 \\
\hline & $\mathrm{Cu}$ & $\mathrm{Pt}$ & $\mathrm{H}_{2}$ activation & Efficient low-temperature uptake, spillover & 19 \\
\hline & $\mathrm{Cu}$ & $\mathrm{Pt}$ & Hydrogenation of acetylene & No loss of activity in presence of $\mathrm{CO}$ & 18 \\
\hline & $\mathrm{Cu}$ & $\mathrm{Pt}$ & $\begin{array}{l}\text { Dehydrogenation of formate to } \mathrm{CO}_{2} \\
\text { and } \mathrm{H}_{2}\end{array}$ & Spillover, selectivity correlates to Pt loading & 21 \\
\hline & $\mathrm{Au}, \mathrm{Ag}$ & $\begin{array}{l}\mathrm{Cu}, \mathrm{Ni}, \mathrm{Pd}, \mathrm{Pt}, \mathrm{Co} \\
\mathrm{Rh}, \mathrm{Ir}\end{array}$ & $\begin{array}{l}\mathrm{CO}_{2} \text { reduction reaction to } \mathrm{C}_{1} \\
\text { hydrocarbons }\end{array}$ & Rh at $\mathrm{Au}(100)$ best calculated activity & 22 \\
\hline \multirow[t]{12}{*}{ Oxides } & $\mathrm{CeO}_{2}$ & Au or Pt & Water gas-shift & Non-metallic Au or Pt species associated with surface & 3 \\
\hline & & & & $\mathrm{CeO}_{2}$ groups vital for activity & \\
\hline & $\mathrm{CoO}$ & $\mathrm{Rh}$ & Hydroformylation of propene & High turnover rate, $94.4 \%$ selectivity & 29 \\
\hline & $\mathrm{Co}_{3} \mathrm{O}_{4}$ & $\mathrm{Rh}$ & Reduction of $\mathrm{NO}$ to $\mathrm{N}_{2}$ & $\begin{array}{l}\text { Singly dispersed bimetallic sites. High turnover rate, } \\
100 \% \text { selectivity }\end{array}$ & 30 \\
\hline & $\mathrm{TiO}_{2}$ nanosheets & Pd ligand stabilized & Hydrogenation of $\mathrm{C}=\mathrm{C}$ bonds & $\begin{array}{l}\text { Performance improvements about one order of } \\
\text { magnitude better than commercial Pd catalyst in some } \\
\text { cases. Stable. }\end{array}$ & 25 \\
\hline & $\mathrm{MnO}_{\mathrm{x}}$ & $\mathrm{Ag}$ & $\mathrm{HCHO}$ oxidation low temperature & Oxygen activation & 31 \\
\hline & $\mathrm{Fe}_{2} \mathrm{O}_{3}$ & $\mathrm{Au}$ & - & $\begin{array}{l}\text { High stability under high temperature (realistic reaction } \\
\text { conditions) }\end{array}$ & 27 \\
\hline & $\mathrm{Fe}_{2} \mathrm{O}_{3}$ & $\mathrm{Pd}$ & Hydrogenations of various alkenes & $\begin{array}{l}\text { SAHCs inactive, small Pd clusters show great catalytic } \\
\text { performance. }\end{array}$ & 10 \\
\hline & $\mathrm{FeO}_{x}$ & $\mathrm{Pt}$ & CO oxidation and PROX & Pt positively charged and strong binding to oxide & 26 \\
\hline & $\mathrm{FeO}_{x}$ & Ir & Water Gas Shift Reaction & Activity increase by one order magnitude (vs. Pt) & 28 \\
\hline & $\mathrm{Al}_{2} \mathrm{O}_{3}$ & $\mathrm{Pt}$ & CO oxidation & Mechanistic study & 32 \\
\hline & $\mathrm{Al}_{2} \mathrm{O}_{3}$ & $\mathrm{Pd}$ & CO oxidation & Low-temperature onset & 33 \\
\hline \multirow{18}{*}{$\begin{array}{l}\text { Carbon } \\
\text { based } \\
\text { materials }\end{array}$} & Graphyne & $\mathrm{Au}, \mathrm{Pt}, \mathrm{Ir}, \mathrm{Rh}, \mathrm{Ru}$ & CO oxidation & Ru catalyst shows most promise at low temperatures & 34 \\
\hline & MWCNT & $\mathrm{Au}$ & $\begin{array}{l}\text { 1,3-butadien hydrogenation with } \\
\text { parahydrogen }\end{array}$ & Order of magnitude better selectivity of SA vs. NP & 35 \\
\hline & $\mathrm{N}$ doped graphene & $\mathrm{Pt}$ & Activation of $\mathrm{O}_{2}$ & Correlation Pt polarization $-\mathrm{O}_{2}$ dissociation & 36 \\
\hline & $\mathrm{N}$ doped graphene & $\mathrm{Pt}$ & CO oxidation & Tri-molecular mechanism & 37 \\
\hline & $\mathrm{N}$ doped graphene & $\mathrm{Pd}$ & $\begin{array}{l}\text { Hydrogenations of alkynes and } \\
\text { nitroarenes }\end{array}$ & Selectivity higher than $90 \%$ & 38 \\
\hline & $\mathrm{N}$ doped graphene & Co & Hydrogen evolution reaction & $\begin{array}{l}\text { Highly active and robust HER catalyst in both acid and } \\
\text { base media }\end{array}$ & 39 \\
\hline & $\mathrm{N}$ doped graphene & $\mathrm{Fe}$ & Oxygen reduction reaction & Active sites reside in plane rather than edges & 40 \\
\hline & $\begin{array}{l}\mathrm{N}-\mathrm{S} \text { co-doped } \\
\text { graphite }\end{array}$ & $\mathrm{Fe}$ & Oxygen electrode reactions & $\begin{array}{l}\text { Bimetalic } \mathrm{Fe}-\mathrm{N}_{\mathrm{x}} \text { sites, superior performance to } \mathrm{Pt}-\mathrm{C} \\
\text { catalyst }\end{array}$ & 41 \\
\hline & $\mathrm{g}-\mathrm{CN}$ & $\mathrm{Pt}$ & $\mathrm{CO}_{2}$ reduction & Photocatalysis & 42 \\
\hline & $\mathrm{g}-\mathrm{CN}$ & $\mathrm{Pt}, \mathrm{Pd}, \mathrm{Co}, \mathrm{Ni}, \mathrm{Cu}$ & Oxygen evolution reaction & Electrocatalytic and photocatalytic potential & 43 \\
\hline & $\mathrm{g}-\mathrm{CN}$ & Co & Oxygen electrode reactions & Comparable activity to precious metal beanchmarks & 44 \\
\hline & $\mathrm{g}-\mathrm{C} 2 \mathrm{~N}$ & $\mathrm{Co}, \mathrm{Cu}, \mathrm{Ni}$ & Oxygen reduction reaction & Stable two atom metal sites, Co-Co proved best & 45 \\
\hline & $\mathrm{mpg}-\mathrm{CN}$ & $P t$, Ir, Pd & Hydrogenation & Stability issues analysed & 46 \\
\hline & Carbon MOF & $\mathrm{Ni}$ & Hydrogen evolution reaction & High durability, about $100 \%$ Faradaic yield & 47 \\
\hline & $\begin{array}{l}\text { OH functionalized } \\
\text { graphite }\end{array}$ & $\mathrm{Au}$ & Acetylene hydrochlorination & $\begin{array}{l}\text { Correlation between formal oxidation state, charge and } \\
\text { activity. }\end{array}$ & 48 \\
\hline & O doped graphene & $\mathrm{Pd}$ & $\begin{array}{l}\text { Hydrogenation of } \\
\text { 1,3-butadiene }\end{array}$ & $\begin{array}{l}100 \% \text { selectivity towards butenes, } 95 \% \text { conversion in } \\
\text { mild reaction conditions }\end{array}$ & 49 \\
\hline & $\begin{array}{l}\text { S modified } \\
\text { graphene }\end{array}$ & $\mathrm{Nb}$ & $\mathrm{O}_{2}$ adsorption and dissociation & $\mathrm{Nb}$ in onion like carbon shell. High durability. & 50 \\
\hline & $\begin{array}{l}\text { S doped graphene } \\
\text { nano-ribbons }\end{array}$ & $\mathrm{Pt}$ & Oxygen reduction to $\mathrm{H}_{2} \mathrm{O}_{2}$ & Stabilises $5 \mathrm{wt} \%$ of atomically dispersed $\mathrm{Pt}$ & 51 \\
\hline
\end{tabular}




\section{Notes and references}

1. J. M. Thomas, Chem. Eur. J., 1997, 3, 6.

2. S. Liang, C. Hao and Y. Shi, ChemCatChem, 2015, 7, 2559-2567.

3. Q. Fu, H. Saltsburg and M. Flytzani-Stephanopoulos, Science, 2003, 301, 4.

4. H. Wei, X. Liu, A. Wang, L. Zhang, B. Qiao, X. Yang, Y. Huang, S. Miao, J. Liu and T. Zhang, Nat Commun, $2014,5,5634$.

5. J. M. Thomas, P. Roy. Soc. A: Mat. Phys. Eng. Sci., 2012, 468, 1884-1903.

6. J. M. Thomas, Nature, $2015,525,2$.

7. A. Wang and T. Zhang, Nat. Energy, 2016, 1, 15019.

8. J. M. Thomas, Z. Saghi and P. L. Gai, Top. Catal., 2011, 54, 588-594.

9. X.-F. Yang, A. Wang, B. Qiao, J. Li, J. Liu and T. Zhang, Acc. Chem. Res., 2013, 46, 8.

10. M. D. Rossell, F. J. Caparrós, I. Angurell, G. Muller, J. Llorca, M. Seco and O. Rossell, Catal. Sci. Technol., 2016, 6, 4081-4085.

11. F. K. Kessler, Y. Zheng, D. Schwarz, C. Merschjann, W. Schnick, X. Wang and M. J. Bojdys, Nature Reviews Materials, $2017,2,17030$.

12. J. M. Thomas, Phys Chem Chem Phys, 2014, 16, 7647-7661.

13. J. M. Thomas and K. D. M. Harris, Energy Environ. Sci., 2016, 9, 22.

14. W. Zhang and W. Zheng, Adv. Funct. Mater., 2016, 26, 2988-2993.

15. J. K. Nørskov, T. Bligaard, J. Rossmeisl and C. H. Christensen, Nat Chem, 2009, 1, 37-46.

16. G. Kyriakou, M. B. Boucher, A. D. Jewell, E. A. Lewis, T. J. Lawton, A. E. Baber, H. L. Tierney, M. Flytzani-Stephanopoulos and E. C. H. Sykes, Science, 2012, 335, 5.

17. G. X. Pei, X. Y. Liu, X. Yang, L. Zhang, A. Wang, L. Li, H. Wang, X. Wang and T. Zhang, ACS Catal., 2017, 1491-1500.

18. J. Liu, F. R. Lucci, M. Yang, S. Lee, M. D. Marcinkowski, A. J. Therrien, C. T. Williams, E. C. Sykes and M. Flytzani-Stephanopoulos, J Am Chem Soc, 2016, 138, 6396-6399.

19. F. R. Lucci, M. D. Marcinkowski, T. J. Lawton and E. C. H. Sykes, J. Phys. Chem. C, 2015, 119, 24351-24357.

20. F. R. Lucci, J. Liu, M. D. Marcinkowski, M. Yang, L. F. Allard, M. Flytzani-Stephanopoulos and E. C. Sykes, Nat Commun, $2015,6,8550$.

21. M. D. Marcinkowski, J. Liu, C. J. Murphy, M. L. Liriano, N. A. Wasio, F. R. Lucci, M. Flytzani-Stephanopoulos and E. C. H. Sykes, ACS Catal., 2017, 7, 413-420.

22. M.-J. Cheng, E. L. Clark, H. H. Pham, A. T. Bell and M. Head-Gordon, ACS Catal., 2016, 6, 7769-7777.

23. M. Yang, L. F. Allard and M. Flytzani-Stephanopoulos, J Am Chem Soc, 2013, 135, 3768-3771.

24. M. Rellán-Piñeiro and N. López, ChemSusChem, 2015, 8, 2231-2239.

25. P. Liu, Y. Zhao, R. Qin, S. Mo, G. Chen, L. Gu, D. M. Chevrier, P. Zhang, Q. Guo, D. Zang, B. Wu, G. Fu and N. Zheng, Science, 2016, 352, 3.

26. B. Qiao, A. Wang, X. Yang, L. F. Allard, Z. Jiang, Y. Cui, J. Liu, J. Li and T. Zhang, Nat Chem, 2011, 3, 634-641.

27. Z. Novotny, G. Argentero, Z. Wang, M. Schmid, U. Diebold and G. S. Parkinson, Phys Rev Lett, 2012, 108, 216103.

28. J. Lin, A. Wang, B. Qiao, X. Liu, X. Yang, X. Wang, J. Liang, J. Li, J. Liu and T. Zhang, J Am Chem Soc, 2013, 135, 15314-15317. 
29. L. Wang, W. Zhang, S. Wang, Z. Gao, Z. Luo, X. Wang, R. Zeng, A. Li, H. Li, M. Wang, X. Zheng, J. Zhu, C. Ma, R. Si and J. Zeng, Nat Commun, 2016, 7, 14036.

30. S. Zhang, L. Nguyen, J. X. Liang, J. Shan, J. J. Liu, A. I. Frenkel, A. Patlolla, W. Huang, J. Li and F. F. Tao, Nat Commun, 2015,6 , 7938.

31. Z. Huang, X. Gu, Q. Cao, P. Hu, J. Hao, J. Li and X. Tang, Angew. Chem. Int. Ed., 2012, 51, 4198-4203.

32. M. Moses-DeBusk, M. Yoon, L. F. Allard, D. R. Mullins, Z. Wu, X. Yang, G. Veith, G. M. Stocks and C. K. Narula, J Am Chem Soc, 2013, $135,12634-12645$.

33. E. J. Peterson, A. T. DeLaRiva, S. Lin, R. S. Johnson, H. Guo, J. T. Miller, J. Hun Kwak, C. H. F. Peden, B. Kiefer, L. F. Allard, F. H. Ribeiro and A. K. Datye, Nat Commun, 2014, 5, 4885.

34. D. W. Ma, T. Li, Q. Wang, G. Yang, C. He, B. Ma and Z. Lu, Carbon, 2015, 95, 756-765.

35. A. Corma, O. G. Salnikov, D. A. Barskiy, K. V. Kovtunov and I. V. Koptyug, Chemistry, 2015, 21, 7012-7015.

36. S. Liu and S. Huang, Carbon, 2017, 115, 11-17.

37. X. Zhang, Z. Lu, G. Xu, T. Wang, D. Ma, Z. Yang and L. Yangd, Phys.Chem.Chem.Phys., 2015, 17, 8.

38. G. Vilé, D. Albani, M. Nachtegaal, Z. Chen, D. Dontsova, M. Antonietti, N. López and J. Pérez-Ramírez, Angew. Chem. Int. Ed., 2015, 54, 11265-11269.

39. H. Fei, J. Dong, M. J. Arellano-Jimenez, G. Ye, N. Dong Kim, E. L. Samuel, Z. Peng, Z. Zhu, F. Qin, J. Bao, M. J. Yacaman, P. M. Ajayan, D. Chen and J. M. Tour, Nat Commun, 2015, 6, 8668.

40. M. J. Workman, A. Serov, L.-k. Tsui, P. Atanassov and K. Artyushkova, ACS Energy Lett., 2017, 1489-1493.

41. P. Chen, T. Zhou, L. Xing, K. Xu, Y. Tong, H. Xie, L. Zhang, W. Yan, W. Chu, C. Wu and Y. Xie, Angew. Chem. Int. Ed., 2017, 56, 610-614.

42. G. Gao, Y. Jiao, E. R. Waclawik and A. Du, J Am Chem Soc, 2016, 138, 6292-6297.

43. X. Li, P. Cui, W. Zhong, J. Li, X. Wang, Z. Wang and J. Jiang, Chem. Commun., 2016, 52, 4.

44. Y. Zheng, Y. Jiao, Y. Zhu, Q. Cai, A. Vasileff, L. H. Li, Y. Han, Y. Chen and S. Z. Qiao, J Am Chem Soc, 2017, 139, 3336-3339.

45. X. Li, W. Zhong, P. Cui, J. Li and J. Jiang, J Phys Chem Lett, 2016, 7, 1750-1755.

46. Z. Chen, S. Mitchell, E. Vorobyeva, R. K. Leary, R. Hauert, T. Furnival, Q. M. Ramasse, J. M. Thomas, P. A. Midgley, D. Dontsova, M. Antonietti, S. Pogodin, N. López and J. Pérez-Ramírez, Adv. Funct. Mater., 2017, 27, 1605785-n/a.

47. L. Fan, P. F. Liu, X. Yan, L. Gu, Z. Z. Yang, H. G. Yang, S. Qiu and X. Yao, Nat Commun, $2016,7,10667$.

48. G. Malta, S. A. Kondrat, S. J. Freakley, C. J. Davies, L. Lu, S. Dawson, A. Thetford, E. K. Gibson, D. J. Morgan, W. Jones, P. P. Wells, P. Johnston, C. R. A. Catlow, C. J. Kiely and G. J. Hutchings, Science, 2017, 355, 5.

49. H. Yan, H. Cheng, H. Yi, Y. Lin, T. Yao, C. Wang, J. Li, S. Wei and J. Lu, J Am Chem Soc, 2015, 137, $10484-10487$.

50. X. Zhang, J. Guo, P. Guan, C. Liu, H. Huang, F. Xue, X. Dong, S. J. Pennycook and M. F. Chisholm, Nat Commun, $2013,4,1924$.

51. C. H. Choi, M. Kim, H. C. Kwon, S. J. Cho, S. Yun, H. T. Kim, K. J. Mayrhofer, H. Kim and M. Choi, Nat Commun, $2016,7,10922$.

52. S. Back and Y. Jung, ACS Energy Lett., 2017, 969-975.

53. X. M. Liu, Y. Tang, E. S. Xu, T. C. Fitzgibbons, G. S. Larsen, H. R. Gutierrez, H. H. Tseng, M. S. Yu, C. S. Tsao, J. V. Badding, V. H. Crespi and A. D. Lueking, Nano Lett, 2013, 13, 137-141.

54. M. Shalom, S. Inal, C. Fettkenhauer, D. Neher and M. Antonietti, J Am Chem Soc, 2013, 135, 7118-7121.

55. X. Wang, K. Maeda, A. Thomas, K. Takanabe, G. Xin, J. M. Carlsson, K. Domen and M. Antonietti, Nat. Mater., 2009 , 8. 
56. P. Miró, M. Audiffred and T. Heine, Chem Soc Rev, 2014, 43, 6537-6554.

57. M. Acik, G. Lee, C. Mattevi, A. Pirkle, R. M. Wallace, M. Chhowalla, K. Cho and Y. Chabal, J. Phys. Chem. C, 2011, $115,19761-19781$.

58. M. K. Richmond, S. L. Scott and H. Alper, J Am Chem Soc, 2001, 123, 5.

59. J. Joubert, F. Delbecq, S. P., E. Le Roux, C. Thieuleux, F. Blanc, C. Coperet, J. Thivolle-Cazat and J. M. Basset, J Am Chem Soc, 2006, 128, 16.

60. M. Moliner, J. E. Gabay, C. E. Kliewer, R. T. Carr, J. Guzman, G. L. Casty, P. Serna and A. Corma, J Am Chem Soc, 2016, 138, 1574315750 .

61. J. Lu, C. Aydin, N. D. Browning and B. C. Gates, Angew. Chem. Int. Ed., 2012, 51, 5842-5846.

62. F. Llabresixamena, A. Abad, A. Corma and H. Garcia, J. Catal., 2007, 250, 294-298.

63. N. Almora-Barrios, S. Pogodin, L. Bellarosa, M. García-Melchor, G. Revilla-López, M. García-Ratés, A. B. Vázquez-García, P. HernándezAriznavarreta and N. López, ChemCatChem, 2015, 7, 928-935.

64. U. Herber, K. Hegner, D. Wolters, R. Siris, K. Wrobel, A. Hoffmann, C. Lochenie, B. Weber, D. Kuckling and S. Herres-Pawlis, Eur. J. Inorg. Chem., 2017, 2017, 1341-1354.

65. L. Bellarosa, C. K. Brozek, M. García-Melchor, M. Dincă and N. López, Chem. Mater., 2015, 27, 3422-3429.

66. C. K. Brozek, V. K. Michaelis, T. C. Ong, L. Bellarosa, N. López, R. G. Griffin and M. Dinca, ACS Cent Sci, 2015, 1, 252-260.

67. S. M. J. Rogge, A. Bavykina, J. Hajek, H. Garcia, A. I. Olivos-Suárez, A. Sepúlveda-Escribano, A. Vimont, G. Clet, P. Bazin, F. Kapteijn, M. Daturi, E. V. Ramos-Fernandez, F. X. Llabres i Xamena, V. Van Speybroeck and J. Gascon, Chem. Soc. Rev., 2017.

68. G. Kresse and J. Furthmüller, Comp. Mater. Sci., 1996, 6, 15-50.

69. G. Kresse and J. Furthmüller, Phys. Rev. B, 1995, 54, 18.

70. J. P. Perdew, J. A. Chevary, S. H. Vosko, K. A. Jackson, M. R. Pederson, D. J. Singh and C. Fiolhais, Phys. Rev. B, $1992,46,6671-6687$.

71. G. Kresse and D. Joubert, Phys. Rev. B, 1999, 59, 18.

72. M. Capdevila-Cortada, Z. Łodziana and N. López, ACS Catal., 2016, 6, 8370-8379.

73. S. Grimme, J. Antony, S. Ehrlich and H. Krieg, J Chem Phys, 2010, 132, 154104.

74. N. López and C. Vargas-Fuentes, Chem Commun (Camb), 2012, 48, 1379-1391.

75. M. García-Melchor and N. López, J. Phys. Chem. C, 2014, 118, 10921-10926.

76. F. Feixas, M. Solà and M. Swart, Can. J. Chem., 2009, 87, 1063-1073. 